\section{Greenland Snow Evidence of Large Scale Atmospheric Contamination for Platinum, Palladium, and Rhodium}

\author{
CARLO BARBANTE,, , \\ AUDREY VEYSSEYRE, $\$$ \\ CHRISTOPHE FERRARI, §, ॥ \\ KATJA VAN DE VELDE, § \\ CHRISTINE MOREL, § \\ GABRIELE CAPODAGLIO,,$\neq$ \\ PAOLO CESCON,, , \\ GIUSEPPE SCARPONI, †, AND \\ CLAUDE BOUTRON*,, , \#
}

Department of Environmental Sciences and Centre for Studies on Environmental Chemistry and Technology-CNR, University of Venice, Ca' Foscari, I-30123 Venice, Italy, Laboratoire de Glaciologie et Géophysique de l'Environnement du C.N.R.S., 54, rue Molière, Boîte Postale 96, 38402 Saint Martin d'Hères, France, Institut des Sciences et Techniques de Grenoble, Université Joseph Fourier de Grenoble, 28, avenue Benoît Frachon, Boîte Postale 53, 38041 Grenoble, France, Istituto di Scienze del Mare, Facoltà di Scienze Matematiche Fisiche e Naturali, Università di Ancona, Via Brecce Bianche, 60131 Ancona, Italia, and Observatoire des Sciences de I'Univers et Unité de Formation et de Recherche de Physique, Université Joseph Fourier de Grenoble (Institut Universitaire de France), Boîte Postale 68, 38041 Grenoble, France

Since 1976 in the United States, Canada, and J apan, and later in other countries, the exhaust system of gasoline powered cars has been equipped with catalytic converters containing Pt and/or Pd and/or Rh. This has resulted in a very significant decrease in urban air pollution for various chemical species such as $\mathrm{NO}_{x_{1}} \mathrm{CO}$, and hydrocarbons. There has however been concern that their ever increasing use might lead to Platinum Group M etals (PGM s) becoming widely dispersed in the environment. From the analysis of Pt, Pd, and Rh in central Greenland recent snow and ancientice using the ultrasensitive inductively coupled plasma sector field mass spectrometry technique, we show here that the concentrations of these metals in snow dated from the mid 1990s are indeed $\sim 40-120$ times higher than in ice dated from 7000 years ago. The fact that such an increase is observed far away from populated areas at a high altitude location indicates there is now a large scale contamination of the troposphere of the Northern Hemis phere for PGMs. Pt/Rh mass ratio in the most recent snow samples is close to the same ratio documented for catalytic converter exhausts in a recent study, which suggests that a large fraction of the recent increase for Pt and Rh might originate from automobile catalytic converters.

\section{Introduction}

During the 1960s the quality of the air in many U.S. and European cities becamea serious problem especially in areas such as Southern California. It was mainly because of the ever increasing emissions of hydrocarbons $(\mathrm{HC})$, carbon monoxide $(\mathrm{CO})$, and nitrogen oxides $\left(\mathrm{NO}_{\mathrm{x}}\right.$ ) from automobile traffic. The strategy which was chosen at that time to reduce these emissions was to equip the new cars with catalytic converters based on heterogeneous catalysis by Platinum Group Metals (PGMs), see e.g. refs 1 and 3 and literature cited herein.

The first cars equipped with such converters appeared in the mid 1970s in Northern America and Japan and much later in Europe (early 1990s). It indeed resulted into a well documented decrease in these emissions. Indirectly, it also resulted in a decrease of environmental lead pollution becausethese converters requirethe use of unleaded gasoline $(4,5)$.

Therehave been four main generation of catalytic exhaust pipes from the mid 1970s to the mid 1990s $(2,3)$. First, from 1976 to 1979, the two-way catalysts containing Pt and Pd which allowed the reduction of the emissions of $\mathrm{HC}$ and $\mathrm{CO}$. Then, from $\sim 1979$ to 1986 , the three-way catalysts containing $\mathrm{Pt}, \mathrm{Pd}$, and $\mathrm{Rh}$ which only reduced the emissions of $\mathrm{NO}_{x}$. Then, from 1986 to 1992, a new generation of three-way catalysts still based on Pt and Rh but better suited to the higher temperatures to which the catalysts were exposed in the new fuel efficient engines. And finally, from 1992 to the mid 1990s, another generation of three-way Pd-rich catalysts used by auto makers both in the U.S. and in Europefor their new models to meet the even stricter emissions legislation. This Pd technology is reflected in the use of $\mathrm{Pd}-\mathrm{Rh}, \mathrm{Pd}$ only, or Pt-Pd-Rh catalysts (1).

For a number of years there has been a concern that the ever increasing use of automobile catalytic converters might lead PGM sto becoming widely dispersed in the environment in theform of micro- and submicrometric particulates, which can be rapidly scavenged close to the source and even transported far away, seee.g. refs 6-15. Considering that the more recent and reliable estimations of the emission factors from the automobile source report a value for Pt of 65-180

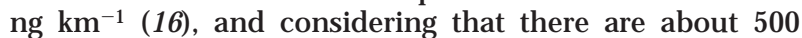
millions cars world wide equipped with catalytic converters and that the average mileage is about $15000 \mathrm{~km}$ per year, then we can roughly estimate an annual Ptemission into the environment, due to catalytic converters, of 0.5-1.4 ton $\mathrm{yr}^{-1}$. Although this represents a very low amount compared with the worldwide emissions of most other trace elements, it cannot be neglected because of the possible accumulation in the environment and enrichment along the food chain. Since there is presently a lack of data on the possible ecotoxicity and toxicity of PGMs, particularly Pd and Rh, it cannot indeed be excluded that this dispersion of increasing quantities of PGM s could lead to potential risks for human health, see e.g. ref 17.

To assess this dispersion of PGMs into the environment, it iscritically important to obtain time series of their changing occurrence in environmental archives from prehuman activities times to present; it is indeed the only way to put

* Corresponding author phone: 33-4-76-82-42-00; fax: 33-4-7682-42-01; e-mail: boutron@glaciog.ujf-grenoble.fr.

+ Department of Environmental Sciences, University of Venice.

₹ Centrefor Studies on Environmental Chemistry and TechnologyCNR, University of Venice.

$\S$ Laboratoire de Glaciologie et Géophysique de l'Environnement du C.N.R.S.

"Institut des Sciences et Techniques de Grenoble, Universitè Joseph Fourier de Grenoble.

$\perp$ Instituto di Sicenze del Mare, Università di Ancona.

\# Observatoire des Sciences de l'Univers et Unité de Formation et de Recherche dePhysique, Universitéjoseph Fourier de Grenoble (Institut Universitaire de France).

VOL. 35, NO. 5, 2001 / ENVIRONMENTAL SCIENCE \& TECHNOLOGY = 835 
into proper perspective the elevated PGMs concentration levels observed in different environmental compartments nowadays (11, $12,15,18,19)$. Unfortunately, the time series which have been obtained so far are for short time intervals only and do not include data for very ancient samples which can allow for the assessment of natural baseline levels (20).

We present here new time series on the occurrence of PGMs in central Greenland snow dated from the late 1960s (i.e. beforetheintroduction of the first automobile converters) to 1995 . We also present data on the natural background concentrations of these metals in ancient ice dated from seven millennia ago. These data were obtained by the ultrasensitive inductively coupled plasma sector field mass spectrometry technique (ICP-SFMS) $(21,22)$. They are interpreted in the light of available information on the different possible natural and anthropogenic sources of PGMs, especially automobile catalytic converters.

\section{Experimental Section}

Description of theSnow and IceSamples. The snow and ice samples were collected in central Greenland at Summit ( $72^{\circ} 34^{\prime} \mathrm{N}, 37^{\circ} 37^{\prime} \mathrm{W}$, elevation $3238 \mathrm{~m}$ ). They were as follows: (a) five snow samples collected from a $2.7 \mathrm{~m}$ snow pit using ultraclean procedures; they cover continuously the period from 1991 to 1995; (b) 22 sections of a 10.7 m snow core covering the period 1969-1988 drilled using an acid-cleaned all-plastic hand-operated auger (5); and (c) two sections of the $3028.8 \mathrm{~m}$ Greenland Ice Core Project (GRIP) deep ice core dated 7260 and 7760 years ago (depths of 1230.4 and $1286.5 \mathrm{~m}$, respectively).

The ancient ice samples will allow for the assessment of past natural Holocene PGM sconcentrations. The1969-1975 samples will be used to assess preautomobile converters anthropogenic changes in PGM s concentrations, while the 1976-1995 samples will be used to try to identify the possible influence of automobile catalytic converters.

Sample Preparation. It was likely that significant contamination was present in theoutsideof thesamples obtained as cores. Each core section was therefore decontaminated by chiselling successiveveneers of snow or ice in progression from the outside to the center of the core using an ultraclean procedure which has been described elsewhere (23). It allowed for obtaining the uncontaminated cylindrical central part of each section.

All samples were melted at room-temperature inside ultraclean (24) low-density polyethylene (LDPE) bottles in a clean laboratory. Aliquots $(0.5-5 \mathrm{~mL}$ depending on available volume) were then taken in $15 \mathrm{~mL}$ LDPE bottles and acidified (1:200 diluted) with ultrapure nitric acid from the National Institute for Standards and Technology (25). The aliquots were frozen again and kept frozen until analysis.

Determination of PGMs. Pt, Pd, and Rh were measured by ICP-SFMS with microconcentric nebulization, using a Finnigan Mat Element instrument (Finnigan, Bremen), as described in detail in ref 22. This technique, thanks to the extremely low noisesignal and thevery high ion transmission, is very attractive for ultratrace determination in environmental matrices $(26,27)$. In particular, it was recently demonstrated that snow and ice, due to the high purity of the matrix, are well suited for direct PGMs determination $(21,22,28)$.

Spectral interferences coming from isobaric atomic ions (such as ${ }^{106} \mathrm{Cd}^{+}$on ${ }^{106} \mathrm{Pd}^{+}$), multiply charged ions (e.g. ${ }^{206} \mathrm{~Pb}^{2+}$ on ${ }^{103} \mathrm{Rh}^{+}$), or polyatomic ions (such as ${ }^{90} \mathrm{Zr}^{16} \mathrm{O}^{+}$and ${ }^{179} \mathrm{Hf}^{16} \mathrm{O}^{+}$ on ${ }^{106} \mathrm{Pd}^{+}$and ${ }^{195} \mathrm{Pt}^{+}$, respectively) and blanks were carefully considered, as described in detail in ref 22 . Using ultrapure water, the blank mean values and (in parentheses) the standard deviations obtained from 30 repetitions were (in $\mathrm{pg} / \mathrm{g})\left(1 \mathrm{pg}=10^{-12} \mathrm{~g}\right)$ as follows: Pt 0.044 (0.0027), Pd 0.31 (0.026), and Rh 0.030 (0.007). The detection limits, calculated

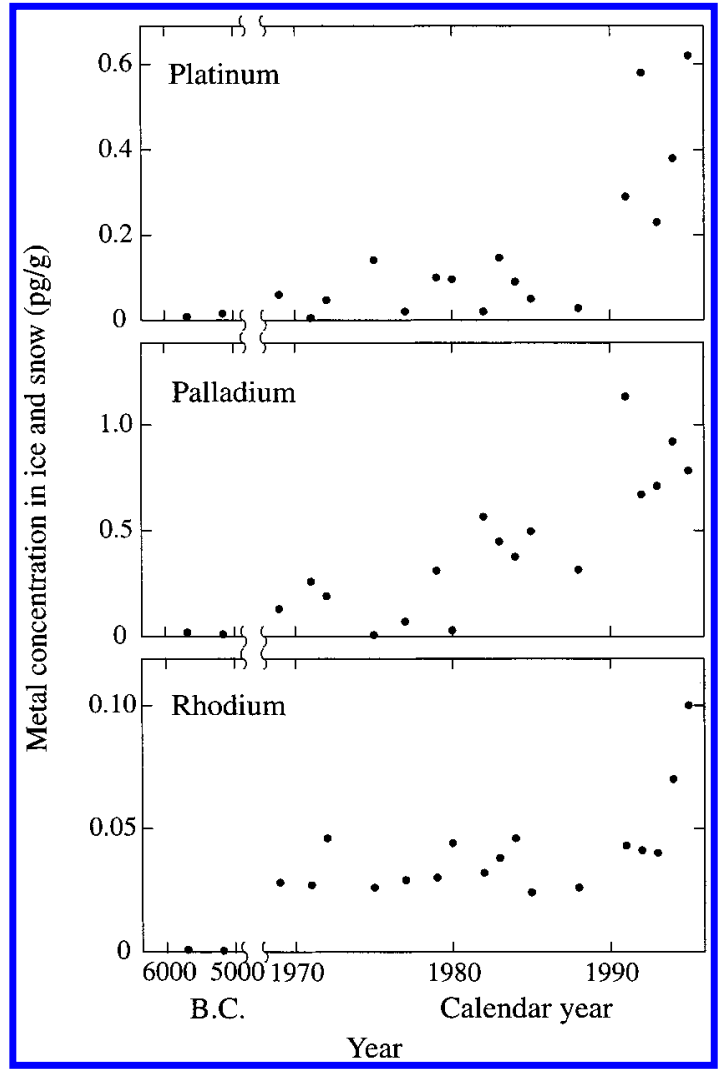

FIGURE 1. Changes in Pt, Pd, and Rh concentrations in central Greenland ice and snow as a function of the age.

as three times the standard deviation of the blanks, were $0.008,0.08$, and $0.02 \mathrm{pg} / \mathrm{g}$ for Pt, Pd, and Rh, respectively.

ICP-SFMSallowed for the directanalysis of all thesamples except for the two ice core sections dated from 7260 and 7760 years ago for which a preconcentration (29) (by factors of 52 and 77, respectively) was required.

The very small available sample volumes were not large enough to allow for performing enough parallel measurements to evaluate the analytical precision of the individual measurements. It was then estimated from 30 consecutive measurements for a high altitude snow sample from the Italian-Swiss Alps in which PGMs concentrations are comparable to those observed in Greenland, as explained in detail in ref 22. Mean PGMs concentrations in the Alpine sample, relative standard deviations (RSD), and 95\% confidence intervals $(\mathrm{Cl})$, from the 30 measurements were as follows: $\mathrm{Pt}$ : mean $0.17 \mathrm{pg} / \mathrm{g}$, RSD $29 \%, \mathrm{Cl} \pm 11 \%$; Pd: mean $0.86 \mathrm{pg} / \mathrm{g}$, RSD $28 \%, \mathrm{Cl} \pm 10 \%$; and Rh: mean $0.061 \mathrm{pg} / \mathrm{g}$, RSD 27\%, $\mathrm{Cl} \pm 10 \%(22)$.

\section{Results and Discussion}

Presentation of the Data. Changes in the concentrations as a function of the age of the ice or snow are shown in Figure 1. To our knowledge, the data reported in Figure 1 are the first PGM s timeseries ever reported for Greenland snow and ice. The only other PGMs time series published before were for different matrices, such as on-shore marine sediments (19), grass (11), urban dust (15), and sewage sludge ashes (12). Most of these other time series are for much shorter time periods and do not include data points for very ancient samples. Also, these other time series are generally of rather local significance only.

Past Natural Occurrence of PGMs in Ancient Ice. Seven millennia ago, PGMs concentrations were extremely low in Greenland ice, $\sim 0.01 \mathrm{pg} / \mathrm{g}$ for Pt and Pd and $0.0007 \mathrm{pg} / \mathrm{g}$ for Rh. At that time, PGMstotally originated from natural sources. 
By combining the Al concentrations measured in each individual sample (average values: $4 \mathrm{ng} / \mathrm{g}$ for the old ice samples; $6.8 \mathrm{ng} / \mathrm{g}$ for the period $1969-1988 ; 7.3 \mathrm{ng} / \mathrm{g}$ for the period 1991-1995) with the PGMs/Al mass ratios in continental crust material $\left(5.16 \times 10^{-9}, 5.16 \times 10^{-9}, 7.75 \times 10^{-10}\right.$ for Pt, Pd, and Rh, respectively) (30) and the PGM concentrations measured in ice and snow, it appears that the rock and soil dust contribution accounts for only $\sim 0.2-0.4 \%$ of PGMsconcentrations in theold ice and about 0.004-0.01\% for the most recent samples.

The input from extraterrestrial dust can be roughly evaluated by combining recent estimates for cosmic dust influx to the wholeEarth (about 150 000t/yr) (31), theaverage content of Pt, Pd, and Rh in cosmic material $(990,560$, and $134 \mathrm{ng} / \mathrm{g}$, respectively) (32), and themean snow accumulation rate at Summit ( $21.5 \mathrm{~g}$ of $\mathrm{H}_{2} \mathrm{O} \mathrm{cm} \mathrm{cm}^{-2} \mathrm{yr}^{-1}$ ) (5). Considering a homogeneous dispersion of cosmic dust over the globe, the maximum natural contribution could account for $\sim 1.3,0.7$, and $0.2 \mathrm{fg} / \mathrm{g}\left(1 \mathrm{fg}=10^{-15} \mathrm{~g}\right)$ i.e., $\sim 13,7$, and $29 \%$ of the total concentration found in the ice dated from seven millennia ago (for Pt, Pd, and Rh, respectively).

Other possible natural sources include volcanic aerosols, which are known to exhibit enhanced PGM s concentrations (33), biomass burning, and forest fires, but available data do not allow for the quantitative evaluation of these other contributions.

Anthropogenic Contributionsin Snow Dated from 1969 to 1975 . Figure 1 shows that in the snow samples dated from 1969 to 1975, i.e., just before the introduction of automobile catalytic converters, Pt, Pd, and Rh concentrations were al ready $\sim 6-, 15-$, and 45 -fold the natural level. It indicates that there was already a large scale contamination of the atmosphere of the Northern Hemisphere for PGMs which could be detected at high altitude sites in the remote central Greenland far away from populated areas.

We are not aware of any published comprehensive inventory of anthropogenic emissions of PGMs into the atmospherefor that period of time. Possible sources include PGMsmining and smelting (1), especially in South Africa (Pt and Rh) and the former Soviet Union (where Pd and Pt are obtained as byproducts of nickel; some of the largest nickel smelters are located in the Russian Arctic, especially in the Kola Peninsula and Noril'sk (1)). Another source is the chemical industry, where PGMs are used as catalysts for various purposes (1), for instance in the production of ammonia or in the petroleum industry (17). Other contributions are from the incineration of refuse, steel and iron manufacturing, and the combustion of fossil fuels. No quantitative data are available for these different possible sources, but our data show that they were intense enough to have strongly enhanced PGMs concentrations above natural levels even in the remote areas of the Northern Hemisphere.

Observed Time Trends in Snow Dated from After 1976. Figure 1 shows different situations during the two decades 1976-1995, i.e., the period which corresponded to the development of automobile catalytic converters. For Pt and $\mathrm{Rh}$, the snow data indicate rather constant concentrations to the late 1980s, followed by higher values for the most recent years. For Pd, on the other hand, they suggest a steady increase, of about $0.03 \mathrm{pg} / \mathrm{g}$ per year, during thewholeperiod. On the whole, concentrations measured in the most recent samplesareabout 40- (Pt), 80- (Pd), and 120-fold (Rh) higher than natural values in ancient ice.

There are various arguments which allow for ruling out any local influence from the summer drilling operations which took place in the Summit area from 1989 to 1993 as part of the Eurocore, GRIP, and GISP2 programs. For instance, the $2.7 \mathrm{~m}$ snow pit was dug $\sim 20$ and $30 \mathrm{~km}$ from the sites of the GISP 2 and GRIP summer camps, respectively. It is more than enough to be free from local influence (34). Also, the vehicles which were used during these operations were not equipped with catalytic converters. In addition, the concentrations of PGMs in diesel fuel, gasoline, or kerosene are extremely small (35).

PossibleAnthropogenic Contributions for the Post 1976 Period. For Pt and Rh, a relatively small contribution from mining and smelting can be predicted because these metals are mainly mined and smelted in the Southern Hemisphere (South Africa) (1). We think that the high concentrations observed after 1990 for these two metals in Greenland snow aremainly linked with increasing emissions from automobile catalytic converters.

This might be supported by the observed changes in the $\mathrm{Pt} / \mathrm{Rh}$ mass ratio in the snow. If we consider the samples dated from 1969 to 1988, the mean ratio is indeed 2.0. The same ratio for the years 1994 and 1995 (calculated from Pt and Rh "excess" concentrations above the mean 1969-1988 values) is 8.5 and 8.3 , respectively. This sharp increase in the $\mathrm{Pt} / \mathrm{Rh}$ ratio clearly shows that a new anthropogenic source became predominant in the mid 1990s.

Interestingly, this $\mathrm{Pt} / \mathrm{Rh}$ ratio of $\sim 8$ is similar to the Pt/ $\mathrm{Rh}$ ratio documented for exhausts from catalytic converters in a recent study (11), then suggesting that automobile catalytic converters might be this new source. It must however be remembered that catalysts technology is permanently shifting, with new mixtures of catalytically effective PGMs being introduced into the market from time to time. Combined with the fact that thereare very few published data on Pt/ Rh ratio for exhausts from catalytic converters and that these data are moreover for local situations and very short time periods only, it makes it presently not possible to define any representative $\mathrm{Pt} / \mathrm{Rh}$ ratio for exhausts from automobile catalytic converters.

For Pd, the steady increase observed from 1969 to 1995 in Greenland snow without significant change in the slope of the temporal curve (Figure 1 ) is thought to mainly reflect emissions of this metal from mining and smelting which, differently from the other two metals (especially Rh), are mainly carried out in the Northern Hemisphere (especially the Russian Arctic) (1).

Finally, it is interesting to calculate correlations among the metals. For Pt and Rh, the correlation coefficient in the precatalytical converter samples is $0.41(p<0.05)$. But if we include the postcatalytical converter samples, the correlation coefficient becomes $0.75(p<0.05)$, further confirming a common source for these two metals. On the other hand, low correlation coefficients are obtained between Pt and Pd and between Rh and Pd both for the pre- and postcatalytical converter samples, in good agreement with our interpretation of a different origin for Pd.

Changes in World Demand for PGMs. Figure 2 shows changes in world demand for PGMs for the recent decades reconstructed from the best available information (1); also shown is world demand for automobile catalytic converters.

After the commercial introduction of automobilecatalytic converters, world PGMs production showed a pronounced increasing trend clearly due to the sharp increment in demand for this recent application, Figure2. This increment in the demand for automobile catalytic converters began in the mid 1980s for Pt and in the early 1990s for Pd. For Rh, no data are available for the years before 1986, but Figure 2 shows a continuously increasing demand for the converters from the mid 1980s onward. Other applications which can compete with autocatalyst production in terms of metal amount treated (e.g. jewel ry for Pt and electrical and dental for Pd) (1) are certainly negligible when considering them with respect to emissions into the atmosphere.

It is interesting to compare the time trends shown in Figures 1 and 2 . It suggests that there has been a time 


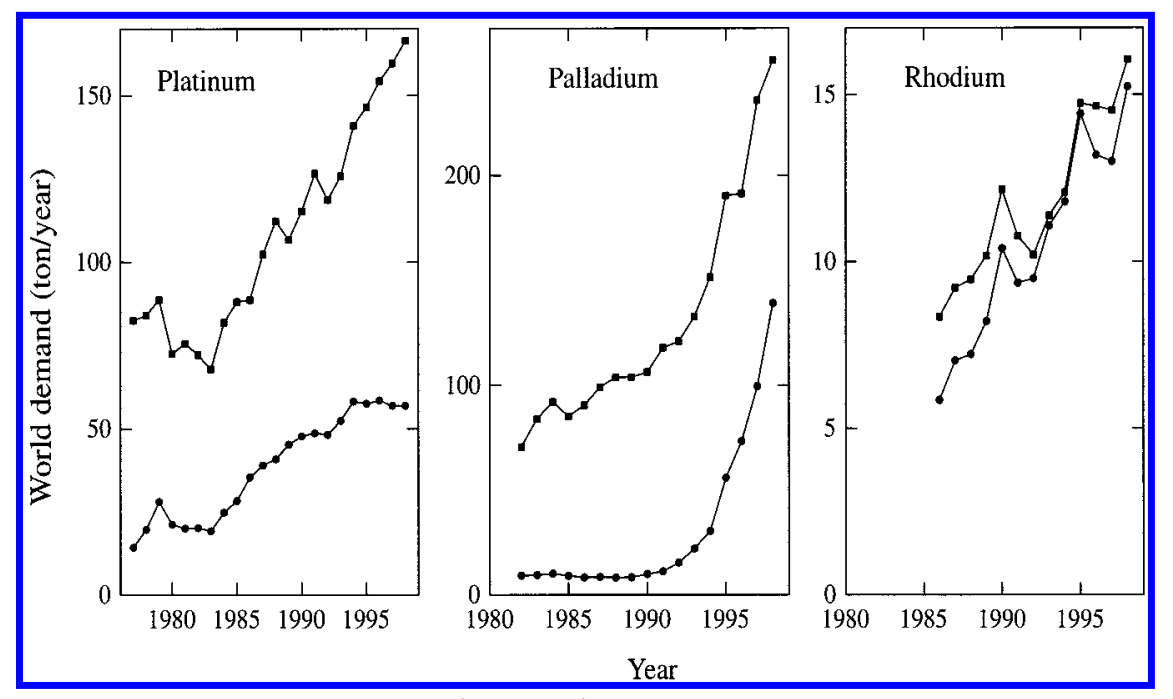

FIGURE 2. Changes in world demand for Pt, Pd, and Rh (from ref 1). Squares: total demand. Circles: demand for automobile catalytic converters.

difference of $\sim 5$ years between the moment of rapid increase in Pt demand for autocatalyst application (mid 1980s, Figure 2) and the increase in Pt concentrations in Greenland snow ( $\sim 1990$, Figure 1$)$. This time interval of $\sim 5$ years can be explained if one considers the delay between metal demand for the construction of catalytic converters and actual use of them in cars. Our data do not allow evidence in such a shift for Rh because of the lack of Rh demand data before 1986.

Interestingly, theobserved changes in the concentrations of Pd in Greenland snow (Figure 1) is consistent with changes in demand for this metal shown in Figure 2: in both cases a 3-fold increase is observed from 1982 to 1995.

Further Studies. The Greenland snow and ice data presented here clearly show that humankind is now contaminating the atmosphere of the Northern Hemisphere with PGM s on a large scale. For Pt and Rh, a large fraction of the contamination now probably originates from automobile catalytic converters, while for Pd this last contribution cannot still be detected in Greenland. It will be now interesting to determine if this contamination can be detected in the most remoteareas of our planet by obtaining time series for PGMs in Antarctic snow and ice. The only Antarctic data for PGMs presently available are unpublished data for surface snow which we have recently obtained: they indicate preliminary values of $\sim 0.8 \mathrm{pg} / \mathrm{g}$ for Pt, $0.5 \mathrm{pg} / \mathrm{g}$ for $\mathrm{Pd}$, and $0.04 \mathrm{pg} / \mathrm{g}$ for Rh.

The fact that this contamination can be seen even at a high altitude location in the remote Greenland indicates that it is certainly spread out all over the populated areas of the Northern Hemisphere. An important question is then to assess possible related health effects. Our present knowledge of possible health effects of PGMs remains very scarce. Moreover, it is mainly for occupationally exposed persons, see for instance refs $8,10,17,35-42$. We suggest that comprehensive studies of possible human health risks be performed.

\section{Acknowledgments}

This work was supported in Italy by ENEA as part of the Antarctic National Research Program (under projects on Environmental Contamination and Glaciology) and in France by the Institut Universitaire de France, the Ministry of the Environment, theAgence del'Environnementet dela M aîtrise del'Energie, the Institut National des Sciences de I'Univers, and the University Joseph Fourier of Grenoble. The core samples were collected within the European programs GRIP and EUROCORE, and the snow pit samples were collected within the European program TAGGSI as part of the joint U.S.-European ATM program. We thankJ. P. Candelone, G. Cozzi, A. Gambaro, U. Görlach, S. Hong, and S. Jay for laboratory assistance and R. J. Delmas, J.-L. Jaffrezo, and C. Rado for field sampling.

\section{Literature Cited}

(1) Johnson Mattey: London, various issues, 1987-1999.

(2) Heck, R. M.; Farrauto, R. J. Catalytic Air Pollution ControlCommercial Technology; Van Nostrand Reinhold: New York, 1995.

(3) Farrauto, R. J.; Bartholomew, C. H. In Fundamentals of Industry Catalytic Processes; Hall, C., Ed.; Blackie Academic and Professional: London, 1997; pp 580-619.

(4) Nriagu, J. O. Sci. Tot. Environ. 1990, 92, 12-38.

(5) Boutron, C. F.; Görlach, U.; Candelone, J. P.; Bolshov, M. A.; Delmas, R. L. Nature 1991, 353, 153-156.

(6) Barefoot, R. R. Environ. Sci. Technol. 1997, 31, 309-314.

(7) Laschka, D.; Nachtwey, M. Chemosphere 1997, 34, 1803-1812.

(8) Helmers, E.; Mergel, N.; Barchet, R. UWSF - Z. Umweltchem. Ökotox. 1994, 6 (3), 130-134.

(9) Helmers, E.; Mergel, N. UWSF - Z. Umweltchem. Ökotox. 1994, 9 (3), 147-148.

(10) Helmers, E. Environ. Sci. Pollut. Res. 1997, 4, 100-103.

(11) Helmers, E.; Mergel, N. Fresenius|. Anal.Chem. 1998, 362, 522528.

(12) Helmers, E.; Schwarzer, M.; Schuster, M. Environ. Sci. Pollut. Res. 1998, 5, 44-50.

(13) Wei, C.; Morrison, G. M. Sci. Total Environ. 1994, 146/ 147, 169174.

(14) Schierl, R.; Fruhman, G. Sci. Total Environ. 1996, 182, 21-23.

(15) Schäfer, J.; Eckhardt, J.; Berner, Z.; Stüben, D. Environ. Sci. Technol. 1999, 33, 3166-3170.

(16) Palacios, M. A.; Gómez, M. M.; Moldovan, M.; Morrison, G.; Rauch, S.; McLeod, C.; Ma, R.; Laserna, J.; Lucena, P.; Caroli, S.; Alimonti, A.; Petrucci, F.; Bocca, B.; Schramel, P.; Lustig, S.; Zischka, M.; Wass, U.; Stenbom, B.; Luna, M.; Saenz, J. C.; Santamaría, J.; Torrens, J. M. Sci. Tot. Environ. 2000, 257, 1-15.

(17) Renner, H.; Schmuckler, G. In Metals and their Compounds in the Environment; Merian, E., Ed.; VCH: Weinheim, 1991; pp 1135-1151.

(18) Balcerzac, M. Analyst 1997, 122, 67R-74R.

(19) Lee, D. S. Nature 1983, 305, 47-48.

(20) Schäfer J.; Eckhardt J.; Berner Z.; Stüben D. Environ. Sci. Technol. 1999, 33, 3166-3170.

(21) Barbante, C.; Cozzi, G.; Capodaglio, G.; Van deVelde, K.; Ferrari, C.; Boutron, C. F.; Cescon, P. L. Anal. At. Spectrom. 1999, 14, 1433-1439.

(22) Barbante, C.; Cozzi, G.; Capodaglio, G.; Van deVelde, K.; Ferrari, C.; Veysseyre, A.; Boutron, C. F.; Scarponi, G.; Cescon, P. Anal. Chem. 1999, 71, 4125-4133. 
(23) Candelone, J. P.; Hong, S.; Boutron, C. F. Anal. Chim. Acta 1994, 299, 9-16.

(24) Boutron, C. F. Fresenius I. Anal. Chem. 1990, 337, 482-491.

(25) Paulsen, P. J.; Beary, E. S.; Bushee, D. S.; Moody, J. R. Anal. Chem. 1988, 60, 971-975.

(26) Moens, L.; Jakubowski, N. Anal. Chem. 1998, 70, 251A-256A.

(27) Jakubowski, N.; Moens, L.; Vanhaecke, F. Spectrochim. Acta 1998, 53B, 1739-1763.

(28) Barbante, C.; Bellomi, T.; Mezzadri, G.; Cescon, P.; Scarponi, G.; Morel, C.; Jay, S.; Van de Velde, K.; Ferrari, C.; Boutron, C. F. I. Anal. At. Spectrom. 1997, 12, 925-931.

(29) Görlach, U.; Boutron, C. F. Anal. Chim. Acta 1990, 236, 391398.

(30) Wedepohl, K. H. Geochim. Cosmochim. Acta 1995, 59, 12171232.

(31) Ceplecha, Z. Astron. Astrophys. 1996, 311, 329-332.

(32) Anders, E.; Grevesse, N. Geochim. Cosmochim. Acta 1989, 53, 197-214.

(33) Zoller, W. H.; Parrington, J. R.; Phelan-Kotra, J. M. Science 1983, 222, 1118-1121.

(34) Suttie, E. D.; Wolff, E. W. Atmos. Environ. 1993, 27A, 18331841.

(35) Alt, F.; Eschnauer, H. R.; Mergler, B.; Messerschmidt, J.; Tölg, G. Fresenius]. Anal. Chem. 1997, 357, 1013-1019.
(36) Rosner, G.; Merget, R. In Immunotoxicity of Metals and Immunotoxicology; Dayan, A. D., etal., Eds.; Plenum Press: New York, 1990; pp 93-102.

(37) Vaughan, G. T.; Florence, T. M. Sci. Total Environ. 1992, 111, 47-58.

(38) Alt, F.; Bambauer, A.; Hoppstock, K.; Mergler, B.; Tölg, G. Fresenius |. Anal. Chem. 1993, 346, 693-696.

(39) Alt, F.; Messerschmidt, J. In Akute und chronischetoxizitat von spurenelemente; Wissenschaftliche Verlagsgesellschaft $\mathrm{mbH}$ : Stuttgart, 1993; Kiel, 1993.

(40) Lustig, S.; Zang, S.; Michalke, B.; Schramel, P.; Beck, W. Fresenius . Anal. Chem. 1997, 357, 1157-1163.

(41) Farago, M. E.; Kavanagh, P.; Blanks, R.; Kelly, J.; Kazantzis, G.; Thornton, I.; Simpson, P. R.; Cook, J. M.; Parry, S.; Hall, G. M. Fresenius]. Anal. Chem. 1996, 354, 660-663.

(42) Pannia Espósito, B.; Faljoni-Alário, A.; Silva de Menezes, J.; Felinto de Brito, H.; Najjar, R. L. Inorg. Biochem. 1999, 75, 5561.

Received for review July 5, 2000. Revised manuscript recei ved November 14, 2000. Accepted December 11, 2000.

ES000146Y 